\title{
Enhancement of the Essential Amino Acid Composition of Food Crop Proteins through Biotechnology
}

\author{
Godson 0. Osuji*, Eustace Duffus, Paul Johnson, Sela Woldesenbet, Aruna Weerasooriya, \\ Peter A. Y. Ampim, Laura Carson, Yoonsung Jung, Sanique South, Edna Idan, \\ Dwiesha Johnson, Diadrian Clarke, Billy Lawton, Alfred Parks, Ali Fares, Alton Johnson \\ Plant Systems Research Unit, College of Agriculture and Human Sciences, Prairie View A \& M University, \\ Prairie View, USA \\ Email: "goosuji@pvamu.edu,cropyielddoublingbiotechnology@yahoo.com
}

Received 17 September 2015; accepted 7 December 2015; published 10 December 2015

Copyright (C) 2015 by authors and Scientific Research Publishing Inc.

This work is licensed under the Creative Commons Attribution International License (CC BY). http://creativecommons.org/licenses/by/4.0/

(c) (i) Open Access

\section{Abstract}

Lack of essential amino acids (EAA) in the diet of at-risk populations could beget a state of food insecurity. Plant proteins are deficient in some essential amino acids. Animals obtain EAA from plant sources. Simple biotechnologies are being developed for improving the EAA composition of crop proteins. The aim was to integrate-discriminate glycolysis and citric-glyoxylic acid cycles to optimize biosynthesis of EAA in food crops. Permutation of diverse metabolic pathways at the mRNA level by glutamate dehydrogenase (GDH)-synthesized RNA is a common biotechnology for doubling the nutritious compositions of plants. Peanuts were planted in plots and treated with mineral salts mixed according to stoichiometric ratios. Protein-bounded and free amino acids of mature peanut seeds were determined by HPLC. GDH-synthesized RNA probes homologous to the mRNAs encoding glyceraldehyde-3-phosphate dehydrogenase (GAPDH), phosphoglycerate mutase (PGlycM), phosphoenolpyruvate carboxylase (PEPCase), enolase, malate dehydrogenase (MDH), isocitrate lyase (ICL), and malate synthase (MS) were prepared from peanut seeds using restriction fragment double differential display PCR method. Northern assays of peanut total RNA showed that the mRNAs encoding PGlycM, PEPCase, MDH, and MS shared extensive sequence homologies that produced a dense network of cross-talks, resulting to co-differential silencing of the mRNAs thereby permuting glycolysis, citric-glyoxylic acid cycles. There were 42 permutations in the NPPKtreated, 105 in control, 420 in KN-, and NPKS-treated peanuts. Because of permutations involving the mRNAs encoding ICL and MS, wherever the abundances of these mRNAs were high (control, and NPPK-treated peanuts) the concentrations of the $\alpha$-ketoglutarate group of total glutamate, glutamine, arginine, proline, and histidine were minimized $(<7.0 \mathrm{mg} / \mathrm{g})$ but the concentrations of the oxaloacetate group of total aspartate, lysine, methionine, threonine, and isoleucine were maxi-

${ }^{*}$ Corresponding author.

How to cite this paper: Osuji, G.O., et al. (2015) Enhancement of the Essential Amino Acid Composition of Food Crop Proteins through Biotechnology. American Journal of Plant Sciences, 6, 3091-3108.

http://dx.doi.org/10.4236/ajps.2015.619302 
mized ( $>28.0 \mathrm{mg} / \mathrm{g})$. The integration of glycolysis, citric and glyoxylic acid cycles increased the quality and doubled the concentrations of the protein-bounded EAA composition of NPPK-treated (33.37 mg/g) compared with the control peanut $(15.66 \mathrm{mg} / \mathrm{g})$. The commanding biotechnology was the stoichiometric mineral salts-based induction of GDH to synthesize the RNAs that integrated glycolysis, citric-glyoxylic acid cycles to one functional unit.

\section{Keywords}

Plant Proteins, Citric Acid Cycle, Glycolysis, Glyoxylate Cycle, HPLC, Glutamate Dehydrogenase-Synthesized RNA, mRNA Co-Silencing, Mineral Nutrients, Permutation of Biochemical Pathways

\section{Introduction}

Efforts have been in progress for many years to improve the nutritious quality, yield, and functionality of plant proteins [1]-[3]. But the proteins of many food crops remain deficient in several essential amino acids (EAAs). The basic 20 amino acids used in protein synthesis are synthesized from some intermediates of glycolysis, and citric acid cycle [4]. Nine EAAs cannot be synthesized in the body and must be acquired from diets. Nonessential amino acids (NEAAs) are synthesized in the body. A deficiency and/or imbalance of an EAA can impair animal growth due to the repression of muscle protein synthesis [5]. Provision of EAA and NEAA in proper ratios is crucial for gastrointestinal, cardiovascular, and reproductive health [6]; and for modulation of neurological and immunological functions [7]. Animals obtain EAA from plant sources. Therefore EAAs derived from crops improve the nutritional quality of food [7]. But it is generally acknowledged that plants are inefficient in the biosynthesis of a balanced essential and nonessential amino acid pool [8]-[10]; and simple biotechnologies are being developed for the improvement of the EAA compositions of food crop proteins. Therefore, lack of EAA in the diet of at-risk populations could beget a state of food insecurity in addition to malnourishment. The aim of this project was to integrate and discriminate glycolysis and citric-glyoxylic acid cycles into a single functional unit so as to optimize the biosynthesis of the EAA in food crops. Also all amino acids except lysine can be synthesized by transaminases which transfer the alpha amino group of glutamate to the alpha-keto acid of an amino acid. In plants, groups of amino acids [8] exist that derive their carbon skeletons from glycerate-3-phosphate (ser, cys, gly), phosphoenol pyruvate (try, phe, tyr), pyruvate (leu, val, ala) in glycolysis; $\alpha$-ketoglutarate (his, pro, arg, glu, gln), and from oxaloacetate (asp, lys, met, thr, ile, asn) in the citric acid cycle. Current biotechnologies to increase the levels of EAA biosynthesis in plants include mutation selection, modification of seed storage proteins, synthesis of new seed storage proteins, alteration of genes encoding enzymes regulating the synthesis of essential amino acids, and application of bacterial genes corresponding to genes encoding plant enzymes controlling EAA [4] [11]. But the proteins of many food crops still remain deficient of one or more EAA. Plant genetics has explored the negative relationship between starch and protein contents to see if maize prolamine accumulation could be increased [12]. Apart from the fact that pyruvate and malate synthesized in glycolysis permeate from cytosol through mitochondrial wall to the citric acid cycle, no mechanism in biotechnology is known to integrate and discriminate glycolysis, citric and glyoxylic acid cycles to one functional unit for the maximum biosynthesis of EAA. An interest in the molecular biology of amino acids production is to learn how EAA are synthesized and how the pathways are integrated so the pathways may be biotechnologically manipulated to increase the amounts of EAA in edible portions of the plant [4].

Glycolysis is finely adjusted [13] at irreversible reaction steps (pyruvate kinase, phosphoglycerate kinase, phosphofructokinase, hexokinase) that command large negative changes in free energy; the big picture being that the flow of carbon intermediary compounds through glycolysis and citric acid cycle is regulated at the enzyme level by feedback substrate inhibition specific to the enzyme. On the other hand, reaction steps with near zero free energy changes catalyzed especially by glyceraldehyde-3-phosphate dehydrogenase (GAPDH), phosphoglycerate mutase (PGlycM), enolase, phosphoenolpyruvate carboxylase (PEPCase) are not regarded as regulatory steps because they are reversible with high accumulation of reactants and products. Although the biosynthesis of amino acids is proportionated into five distinct groups [8], several discussions have neatly demarcated the biosynthesis of 
each amino acid as enzyme-specific and different from the others [14]. Therefore, integrative amino acid biosynthesis is still in infancy. The approach adopted hereunder is integrative in molecular biology, focusing on the glycerate-3-phosphate, pyruvate, phosphoenol pyruvate, $\alpha$-ketoglutarate, and oxaloacetate groups of amino acids. A chemical advantage of the integrative approach is that it is supported by the free energy changes in glycolysis and citric-glyoxylic acid cycles, the low exergonic reactions producing a buildup of the substrates for amino acid biosynthesis, whereas the large exergonic steps produce metabolic energy. Low exothermic reaction steps are essentially at equilibrium in the cell; substrate and/or product accumulation occurs slowing down the metabolic fluxes and thus creating opportunities for spin-off biosynthesis of amino acids. But no molecular studies at the mRNA level have been conducted to illuminate the integration and discrimination regulations of glycolysis, glyoxylic and citric acid cycles for optimal biosynthesis of amino acids. The reaction steps that are non-exergonic (GAPDH, PGlycM, enolase, malate dehydrogenase, PEPCase, isocitrate lyase, and malate synthase) may embody the molecular mechanisms that stabilize the biosynthesis of amino acids and proteins, the EAA nutritious quality of food crops in particular, and the doubling of crop dry matter yield in general. Nature has shown that we must not be complacent about dry matter and nutritious crop yields because climate can adversely change the terrestrial ecosystems and crop yield through depletion of soil organic matter, mineral nutrients, and water-holding capacity of soil [15].

Integration and discrimination of diverse metabolic pathways at the mRNA level (permutation) is the biotechnological approach for doubling of crop dry matter, fatty acid, protein, and cellulosic biomass yields; for production of allergen-free low-linoleic acid, and ultra-high resveratrol peanuts [16]-[18]. In the approach, glutamate dehydrogenase (GDH) of the crop is induced to isomerize and to synthesize RNAs that are homologous to mRNAs encoding some regulatory enzymes [19]. Messenger RNA is silenced by GDH-synthesized RNA that is homologous to it leading to knock-out, or knock-down of respective enzyme, and to decreased metabolic reaction product of the enzyme [18]. Such mRNAs may also become co-silenced, causing differential synthesis of respective metabolic intermediates [20]. The structure of the signaling RNA molecules that permute and integrate glycolysis, citric and glyoxylic acid cycles had not been described.

Peanut was chosen for this study because it is the most popular nut-snack in the world [21]. India, China, Nigeria, and USA produce about $80 \%$ of the world crop [22]. Peanut is also ideal because its formulations are being prescribed as therapy for the nutritional management of kwashiorkor, a protein-nitrogen state of severe malnourishment that is afflicting infants and elderly mothers in some arid zones of Africa [23]. Therefore, lack of essential amino acids in the diet of at-risk populations begets a state of food insecurity [24].

Hereunder, results show that GDH-synthesized RNAs homologous to the mRNAs encoding the enzymes that catalyze the non-exergonic reaction steps coordinately regulate the abundances of the mRNAs thereby integrating glycolysis and citric-glyoxylic acid cycles leading to reciprocal increases in the concentrations of amino acid groups in general and to maximized concentrations of the EAA compositions of peanut proteins.

\section{Experimental Procedures}

1) Treatment of peanuts with mineral ion solutions: Peanut (Arachis hypogaea L. Virginia) seeds were planted in $120 \times 120 \times 30 \mathrm{~cm}$ (width $\times$ length $\times$ depth) boxes, each filled with 3 bags of professional growing mix (Sungro Horticulture, Bellevue, Washington, USA) mixed with 2 bags of organic matter-rich top soil (Landscapers Pride, New Waverly, Texas, USA). Each box was set up on level ground in the field on a weedblocking plastic mat. About 25 seeds were planted per box. There was replanting to make up for ungerminated seeds. The applied mineral ion compositions were based on the model stoichiometric combinations [17], and to mimick the binomial subunit polypeptide compositions of the GDH isoenzymes [16]. The first box was left as the untreated control; the second box (NPKS) was treated with $1 \mathrm{~L}$ of combined $\mathrm{NH}_{4} \mathrm{Cl}(25 \mathrm{mM}), \mathrm{Na}_{3} \mathrm{PO}_{4}(20$ $\mathrm{mM}), \mathrm{Na}_{2} \mathrm{SO}_{4}(50 \mathrm{mM})$, and $\mathrm{KCl}(4 \mathrm{mM})$ solution; the third box (NPPK) was treated with $1 \mathrm{~L}$ of combined $\mathrm{NH}_{4} \mathrm{Cl}(25 \mathrm{mM}), \mathrm{Na}_{3} \mathrm{PO}_{4}(40 \mathrm{mM})$ and $\mathrm{KCl}(4 \mathrm{mM})$ solution; the fourth box $(\mathrm{KN})$ was treated with $1 \mathrm{~L}$ of combined $\mathrm{NH}_{4} \mathrm{Cl}(25 \mathrm{mM})$ and $\mathrm{KCl}(4 \mathrm{mM})$ solution. The boxes were watered every other day. Mineral nutrient solutions were applied sequentially, first at pre-flowering stage ( 2 weeks after seed germination), second at flowering, and third at post-flowering. When the leaves turned yellow (peanut maturity), pods were harvested, allowed to dry on the greenhouse floor for about 2 weeks, weighed, shelled by hand, and the kernels (seeds) and shells weighed separately. Seeds were stored at $-30^{\circ} \mathrm{C}$.

2) Analyses for peanut yield: Dry and milled (composited) seeds (100 g) per experimental treatment, sent to NPA Laboratories, Santa Ana, CA, USA were custom analyzed for free amino acids, protein-bounded amino 
acids, and total crude protein. HPLC AccQ-Tag method with modifications [25] was applied for amino acid quantitation; Kjeldahl method was applied for crude protein quantitation.

3) Purification of GDH Isoenzymes: GDH was extracted from peanut seeds (30 g) by homogenization at $4{ }^{\circ} \mathrm{C}$ with $100 \mathrm{~mL}$ of buffer [26] containing 5 units per $\mathrm{mL}$ of each of RNase A and DNase 1 (Applied Biosystems, Foster City, CA, USA) and subjected to fractional $\left(\mathrm{NH}_{4}\right)_{2} \mathrm{SO}_{4}$ precipitation, preparative-scale isoelectric focusing (IEF; Rotofor, Bio-Rad, Hercules, CA, USA) followed by dialysis of the fractions as described before [27]. Rotofor fractions $(0.2 \mathrm{~mL})$ were purified by native $7.5 \%$ polyacrylamide gel electrophoresis (PAGE; Protean II cell, Bio-Rad); at $100 \mathrm{~V}, 20 \mathrm{~h}, 4^{\circ} \mathrm{C}$ to remove other proteins, and nucleic acid contaminations. GDH isoenzymes were eluted ( $30 \mathrm{~min}, 100 \mathrm{~V}$ ) from the electrophoresed gel with $0.05 \mathrm{M}$ solution of Tris base at subzero temperature using mini-whole gel eluter (Bio-Rad) as described before [28].

RNA synthetic activity of GDH isoenzymes [16] was assayed in combined deamination and amination substrate solutions of $0.1 \mathrm{M}$ Tris- $\mathrm{HCl}$ buffer $\left(\mathrm{pH}\right.$ 8.0) containing the four NTPs (0.6 mM each), $\mathrm{CaCl}_{2}(3.5 \mathrm{mM})$, L-glu $(3.23 \mu \mathrm{M}), \mathrm{NAD}^{+}(0.375 \mu \mathrm{M}), \mathrm{NH}_{4} \mathrm{Cl}(0.875 \mathrm{mM}), \alpha$-ketoglutarate $(10.0 \mathrm{mM}), \mathrm{NADH}(0.225 \mathrm{mM}), 5$ Units RNase inhibitor, 1 Unit DNase 1, and $5 \mu \mathrm{g}$ of actinomycin D. Reaction was started by adding $0.2 \mathrm{~mL}$ of whole gel-eluted GDH charge isomers containing 4 - $9 \mu \mathrm{g}$ protein per mL. Final volume of the reaction was brought to $0.4 \mathrm{~mL}$ with $0.1 \mathrm{M}$ Tris- $\mathrm{HCl}$ buffer $\mathrm{pH} 8.0$. Reactions were incubated at $16^{\circ} \mathrm{C}$ overnight and stopped by phenol-chloroform ( $\mathrm{pH}$ 5.5) extraction of the enzyme. RNA was precipitated with ethanol, and dissolved in minimum volume of molecular biology quality water. RNA yield and quality were determined by photometry and by agarose gel electrophoresis. Assays were carried out in duplicate to verify the reproducibility of the results.

4) cDNA synthesis, cloning, characterization, and probe selection: cDNAs were synthesized with $2 \mu \mathrm{g}$ of each product RNA synthesized by the whole gel-eluted GDH charge isomers using random hexamer primer. Restriction fragment PCR amplification; adapter ligation; sequencing gel fractionation; and purification of cDNA fragments [16] were conducted according to the methods of Display Systems Biotech, Vista, CA, USA except that $15 \mu \mathrm{L}$ instead of $3 \mu \mathrm{L}$ of the amplified reaction solution was loaded into the sequencing gel. All the 64 Display Probes were applied for the restriction fragment PCR amplifications. Selected cDNA fragments from the sequencing gel were subcloned into pCR4-TOPO vector and transformed into TOP10 One Shot Chemically Competent Escherichia coli (Invitrogen, Carlsbad, CA), followed by overnight growth on selective plates. Up to ten positive transformant colonies were picked per plate and cultured overnight in LB medium containing 50 $\mu \mathrm{g} / \mathrm{mL}$ of kanamycin. Plasmid DNA was purified with a plasmid kit (Novagen, Madison, WI). The insert cDNA was sequenced with T3 and T7 primers by Functional Biosciences, Inc. (Madison, WI, USA). To identify the GDH-synthesized RNAs that were homologous to mRNAs encoding the enzymes of glycolysis, citric-glyoxylic acid cycle, the cDNA sequences were used as queries to search the NCBI nucleotide-nucleotide (excluding ESTs) BLAST (blastn), and non-redundant protein translation (blastx) databases. cDNAs that displayed the highest alignment scores with mRNAs encoding the enzymes were selected as the probes.

5) Total RNA: Total RNA was extracted from peanut seeds harvested from the control or mineral-treated boxes using the acidic phenol/chloroform (pH 4.5) method [29].

6) Northern blot analysis: Equal amounts $(20 \mu \mathrm{g})$ of RNAs synthesized by GDH charge isomers from the control and mineral nutrients-treated peanuts were loaded, briefly electrophoresed on $2 \%$ agarose gels, stained with ethidium bromide, and photographed to verify RNA quality. RNA was electro-transferred from the electrophoresed gel onto Brightstar-Plus nylon membrane (Applied Biosystems, Foster City, CA, USA) as described before [30]. To verify completeness of the electro-transfer of total RNA, the transfer was continued on to a second Brightstar-Plus nylon membrane.

The cDNAs that were used as Northern probes were those homologous to mRNAs encoding GAPDH, PGlycM, isocitrate lyase (ICL), PEPCase, enolase, malate synthase (MS), and malate dehydrogenase (MDH). For the labeling of the cDNA probes, cDNA inserts were amplified by PCR from the corresponding plasmids (15ng) using M13 forward and M13 reverse primers ( $2 \mu \mathrm{M}$ each), $\left[{ }^{32} \mathrm{P}\right]-\mathrm{dATP}(6000 \mathrm{Ci} / \mathrm{mmol}, 20 \mathrm{mCi} / \mathrm{mL})$, dCTP/dGTP/TTP mix $50 \mathrm{mM},(2 \mu \mathrm{L})$, and Taq polymerase (1U), in a final volume of $50 \mu \mathrm{L}$. Amplification was according to Display Systems Biotech (Vista, CA, USA) "touch-down" PCR procedure (denature: $94^{\circ} \mathrm{C}, 1 \mathrm{~min}$ for the first 10 cycles: $94^{\circ} \mathrm{C}, 30 \mathrm{sec}$; anneal: $60^{\circ} \mathrm{C}, 30$ sec for the first cycle, then reduced the temperature $0.5^{\circ} \mathrm{C}$ each cycle until an annealing temperature of $55^{\circ} \mathrm{C}$ was reached after 10 cycles; extension: $72^{\circ} \mathrm{C}, 1$ min.; continued another 25 cycles with $94^{\circ} \mathrm{C}, 30 \mathrm{sec} ; 55^{\circ} \mathrm{C}$, $30 \mathrm{sec} ; 72^{\circ} \mathrm{C}, 1 \mathrm{~min}$; final extension $72^{\circ} \mathrm{C}, 5 \mathrm{~min}$ ). Unincorporated nucleotides were removed from the labeled cDNA inserts by chromatography through short column of sephadex G50.The first and corresponding continuation nylon membranes with immobilized RNA were prehybri- 
dized with ULTRAhyb buffer and hybridized with ${ }^{32} \mathrm{P}$-labeled cDNA inserts as probes overnight at $68^{\circ} \mathrm{C}$ as described before [19]. Solutions of labeled cDNA were first heated in boiling water bath for 10 min before adding to the prehybridized membrane. After hybridization, the membranes were washed $\left(30 \mathrm{~min}, 68^{\circ} \mathrm{C}\right)$ with NorthernMax (Applied Biosystems, Foster City, CA, USA) low stringency wash solution followed by several NorthernMax high stringency washes $\left(30 \mathrm{~min}, 68^{\circ} \mathrm{C}\right.$ ) until all loosely bound probes were removed. The damp membrane was autoradiographed by exposure to X-ray film within intensifying screens at $-80^{\circ} \mathrm{C}$. Northern band intensities were digitalized using UN-SCAN-IT gel digitalizing software (Silk Scientific, Inc., Orem, Utah, USA). The digital band intensities for mRNA(s) encoding each enzyme were rated on a scale of $0 \%$ (lowest band intensity, fully silenced) to $100 \%$ (highest band intensity, not silenced). Northern blots were repeated at least three times for each mRNA encoding the non-exergonic enzymes.

\section{Results and Discussion}

\subsection{Demonstration of Silencing of mRNAs Encoding the Non-Exergonic Enzymes}

The mineral nutrient-wide RNA populations synthesized by peanut GDH were exhaustively searched for sequences that were homologous to the mRNAs encoding the enzymes of glycolysis, citric and glyoxylic acid circles. Only one single homologous RNA copy was identified per mRNA encoding ICL, MS, MDH, enolase, PEPCase, PGlycM, and GAPDH. The probes were the cDNAs of the GDH-synthesized RNAs (Table 1). The seven enzymes are those that catalyze the non-exergonic reaction steps and give rise to the biosynthesis of amino acids via respective intermediates of glycolysis, citric and glyoxylic acid cycles.

The Northern blots were important for determining the threshold quantities of the mRNA in total RNA that were homologous to the Northern probes, and for detecting the homologous mRNAs. Over-load by up to $25 \mu \mathrm{g}$ total RNA per agarose gel well (Figure 1 and Figure 2) was required in order to Northern blot detect those low

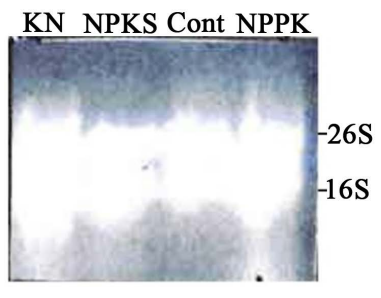

(a)

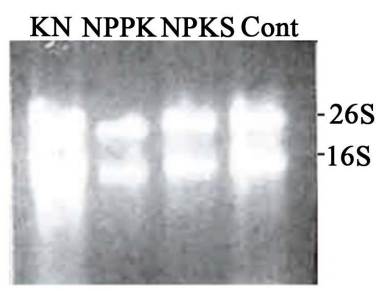

(c)

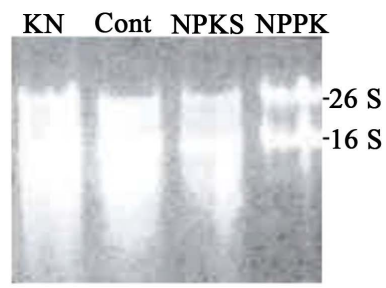

(e)

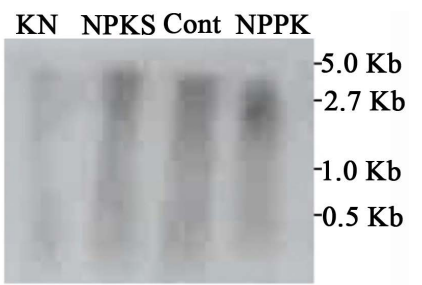

(b)

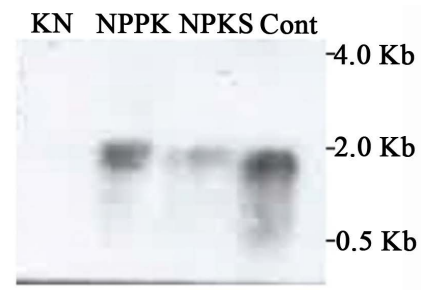

(d)

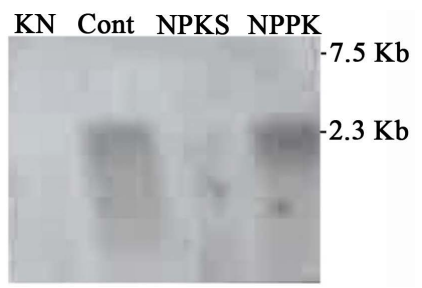

(f)

Figure 1. Northern blot analyses of peanut mRNAs encoding Phosphoenol pyruvate carboxylase ((a), (b)), Malate synthase ((c), (d)), and Malate dehydrogenase ((e), (f)). Twenty micrograms total RNA was electrophoresed through ethidium bromide-treated $2 \%$ agarose gel ((a), (c), (e)), transferred to Nylon membrane, then hybridized with ${ }^{32}$ P-labeled cDNA probe 53M, (b), probe 96K, (d), probe 15f, (f). Ethidium bromide staining of rRNA bands ((a), (c), (e)) indicated RNA integrity and reproducibility of loading. 
Table 1. Some cDNA sequences of the RNAs synthesized by Peanut GDH, their homologous mRNAs, and the encoded enzymes of glycolysis, and citric/glyoxylic acid cycle.

\begin{tabular}{|c|c|c|}
\hline $\begin{array}{l}\text { cDNA } \\
\text { Probe \# }\end{array}$ & $\begin{array}{l}\text { Enzymes and } \\
\text { mRNA accessions }\end{array}$ & cDNA sequences of the GDH-synthesized RNAs homologous to peanut mRNAs \\
\hline $56 \mathrm{~N}$ & $\begin{array}{l}\text { glyceraldehyde-3-phosphate } \\
\text { dehydrogenase } \\
\text { (non-phosphorylating, NADP): } \\
\text { gb|AAO38512.1| }\end{array}$ & $\begin{array}{c}\text { GGNNGNCGCGGNANGCGCGGNNNCAGNGCGNTGGGGNCGGNNGNANNNNNGCG } \\
\text { GNNCGNGAAGTGGGGNAANCGAGGGTAAANANNGAGAAGGNNGTAGTNATCGG } \\
\text { GGAANGCAGTNTACNCGNACCAGTANGNATTCTACCAGACCNTANGGGCNAATT } \\
\text { CNNTTAAACCTNCTTGNCTAGTCCCTTTANTNNGGGTTAATTCTGANCTTGGCGAA } \\
\text { NTCATGNNCNTAGCTNGTTTCCNGANTCNTAGCNCATCTCGGATACAAAANTATG } \\
\text { CTGCATGGNCCCTTAATNCNANCCCTCCTGAATTCCAGCACGCNGGCGGCCNTNN } \\
\text { CTNATGGA }\end{array}$ \\
\hline $10 \mathrm{E}$ & $\begin{array}{l}\text { phosphoglyceromutase } \\
\text { ID: emb|X70652.1| }\end{array}$ & $\begin{array}{l}\text { GGGTTGAAATACGGCGCGATTGCCCTTTGAGTCTGACCGAATCGGGGTTGAATGC } \\
\text { CAAGGGATCTAGAAATGCATCATCGGGTACGCAGTCTACGAGCCAGTAA }\end{array}$ \\
\hline $60 \mathrm{~F}$ & enolase ID: emb|Z28386.1| & $\begin{array}{l}\text { GGAGGGGCGCGCGAAAGCCCTTAACGNGNTTGNCAGAACTGAGGAATGCGTGTN } \\
\text { CGGTACTNCATCNACGGGACATANGGANGGCGTGTTTCAGCGNTGGACCGGCAG } \\
\text { ATTACCCACNTAGGGCNTAGGTANGGNNCGAGGGACAANAANCTCTTCTTTGAA } \\
\text { CAGGGGGTCCAGATTCAATCCGGTCGTATAGACNTTTGATCTCCATGNCTTCCGA } \\
\text { TTCGGTCAGGACTCATAAGGGCGAATTCNTTTAAACCTGCANGACTAGTCCCTTT } \\
\text { AGTGAGGGTTAATTCTGAGCTTGGCG }\end{array}$ \\
\hline $53 \mathrm{M}$ & $\begin{array}{l}\text { phosphoenolpyruvate } \\
\text { carboxylase ID: } \\
\text { gb|ABR29878.1| }\end{array}$ & $\begin{array}{l}\text { TGGCGGGCGGGAAANCNCTAACGANTNCGGAACGAAANCGTAGAGTGGGAGTA } \\
\text { ACAGCGGTNAACGGGCGTGTGGTNCCTGTGGTGAANNNTNNCCCCGAATTNAGT } \\
\text { NCGGGCGGGGTAACGTCGTTCAAGGGCATCCTTCGGATAACTACGGGACCTTCAT } \\
\text { GGAGTTGGGCTTGGGGGTTGGTGATATCATTCCGTAACTCGGAAAATGATGTTA } \\
\text { TTCCTCGGGTACGCAGTCTACGAGACCAGTAAGGGCG }\end{array}$ \\
\hline $15 \mathrm{D}$ & $\begin{array}{l}\text { isocitrate lyase ID: } \\
\text { gb|M17145.1|RCCICL4 }\end{array}$ & $\begin{array}{l}\text { ATGAAACGCGCGATTCCCCTTATGAGTCTGACCGAATCCTTCCGGCAATCCTTGA } \\
\text { GGGCTTGGCTCACGTTTATCTTTCGGCAGAGGGAGACTGGTGAAGTTAGGTTTAC } \\
\text { CTTGGAACTCATCATCGGGTTCACCAACACCTTCAGGAGCTTTAGGTTCACCTACC } \\
\text { GGTGGAGGTGGAGGAGTAGGCATGGTTCTAGGTTGTGGTACTTGTGGGGCTTGCG } \\
\text { GCTGTGTAGATGGATCTGCCGCAGGTTCACCGCTAGGAGGAGGACTACCGGCTGT } \\
\text { TGATTAGGCTGTACCATCCCGCCCATACCCGCAGTCTACGAGACCAGTAA }\end{array}$ \\
\hline $96 \mathrm{~K}$ & $\begin{array}{l}\text { malate synthase ID: } \\
\quad \text { emb|X52806.1| }\end{array}$ & $\begin{array}{l}\text { CAAANCGGCGCGNATTGCCCCTTCGGAGCTCGTGNNACANCGTATCACCCGAAG } \\
\text { ATTNNTGCCGAGANCTCAANTANTNGNGTCGCATGCNTCCTNNTGCAANGCCAGG } \\
\text { GTGNATNANNGGCATGAAACTATNTCCATGTCGTTCNTGCATTGTATCNGGCTTN } \\
\text { TTGNGGCNACGACAGTTCTTTCGAGCACNANCTATNACANGNCNACGGAATATTC } \\
\text { ATGNNNCGCGAACTCTTANTCANCACCCAGANACGGTCANCTCTAACAACGNAC } \\
\text { CCANGCNACCCNACGTACTATCGAAGAACCAGNTATAGCGACGTCGTACATAGA } \\
\text { CTCNGTNACGTCATCANNGAGCCGAAATTCCATNCTATNNCCTGGCAGGTACTAG } \\
\text { CNCCGTGNTANCTGNGGGNTNAATTGCTNTATGCNNGTGCGTCAATCACCGGGCC } \\
\text { ATACACGGATTTCCNGAAGACAAATCACCNTCGGGTACGCAGTCTACGAGACCA } \\
\text { GTACGCANTCTACAGACC }\end{array}$ \\
\hline $15 \mathrm{~F}$ & $\begin{array}{l}\text { NADP-dependent } \\
\text { malate dehydrogenase ID: } \\
\text { gb|AF262997.1| }\end{array}$ & $\begin{array}{l}\text { TGGTTTCCGATCGCGCGATTGCCCTGGTGACTGCGGATTCGGTCAGGACTCATAG } \\
\text { CCACTGGTCTCGTAAACTGCGTACTCGGTCAGGACTCATCGCTACTGGTCTCGTAA } \\
\text { GACTGCGTACTGGTCTCGTAGACTGCCGTACCGGTCTCGAGACTGCGTACTGGTC } \\
\text { TCGTAGACTGCGTACTCGGTCAGGACTCATCGCTGATTCGGTCAGGACTCATAA }\end{array}$ \\
\hline
\end{tabular}

copy numbers of the mRNAs encoding ICL, MS, MDH, enolase, PEPCase, PGlycM, and GAPDH. The Northern blot results (Figure 1 and Figure 2) demonstrated galaxies of co-silencing and differential silencing of mRNAs by GDH-synthesized RNAs as seen before [16] [17] [19]. The several high stringency Northern Max washes of Northern membranes confirmed that the base-pair binding of the cDNA probe to its targets in mRNA was tenacious, and also showed that hybridization reaction was very specific. The continuation trans-blotted nylon membrane gave very faint to no Northern bands thus confirming that transfer of mRNA to the first membrane was complete. The compactness of the rRNA bands on the ethidium bromide-stained agarose gels (Figure 1 and Figure 2) showed that the total RNA preparations applied for Northern hybridization were not degraded. The replicate Northern blots per mRNA encoding a non-exergonic enzyme gave identical band patterns thus confirming the hybridization was a specific and reproducible reaction.

1) Phosphoenolpyruvate carboxylase: The Northern band population (Figure 1(b)) obtained using the cDNA probe for the mRNA encoding PEPCase showed that they were about $2.7 \mathrm{~kb}$ molecular weight similar to that of other higher plants [31] [32]. The mRNA encoding PEPCase was silenced in KN-treated peanut, partially silenced 


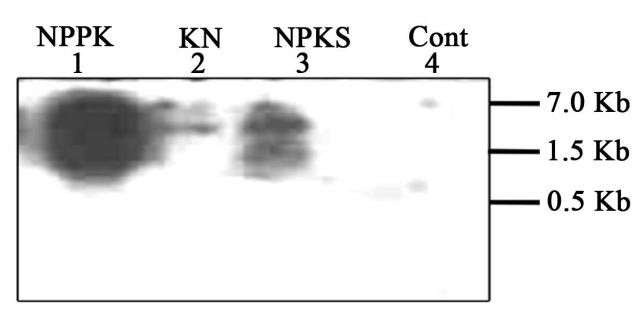

(a)

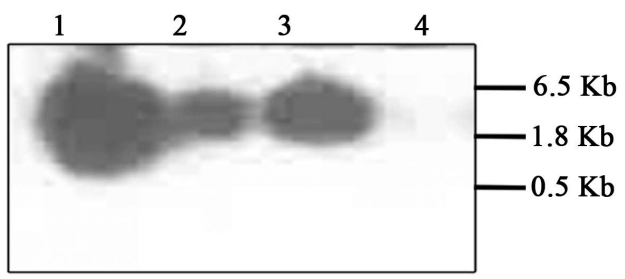

(b)

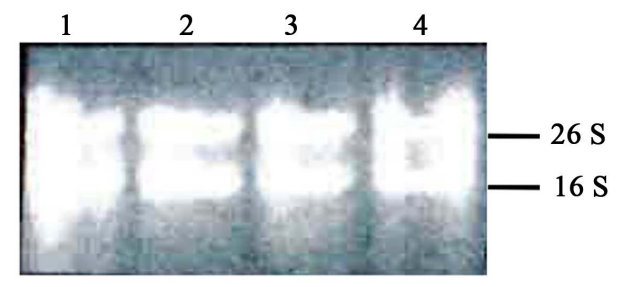

(c)

Figure 2. Northern blot analyses of peanut mRNAs encoding (a) Glyceraldehyde-3-phosphate dehydrogenase; (b) Phosphoglycerate mutase. Twenty micrograms total RNA was electrophoresed through ethidium bromide-treated $2 \%$ agarose gel (c), transferred to Nylon membrane, then hybridized with ${ }^{32}$ P-labeled cDNA probe 56N, (a), probe 10E, (b). Ethidium bromide staining of rRNA bands (c) indicated RNA integrity and repeatability of loading.

in NPKS-treated peanut, but was not silenced in control, and NPPK-treated peanut (Figure 1(b)). The PEPCase cDNA probe (Table 1) matched three times within the mRNA encoding PEPCase, two of the matches were plus/plus sequence homologies while one was minus/plus. These complex matches of the cDNA probe to the PEPCase mRNA made for such tenacious in vitro binding that several high stringency washes of the hybridized nitrocellulose membranes (at $65^{\circ} \mathrm{C}$ for $4-5 \mathrm{~h}$ ) were done in order to clean-out the Northern membranes (Figure 1(b)). The crisscross binding in vivo between the GDH-synthesized RNA and the mRNA encoding the PEPCase assured liquefaction specificity of the mRNA silencing reaction. The molecule that induced the mRNA silencing in vivo was the molecule that was applied in vitro to demonstrate the abundance of the mRNA. Therefore, the Northern population of bands (Figure $1(b)$ ) is the demonstration of the silencing of the mRNA encoding PEPCase. The enzyme is located in the leaf cell cytosol where it converts phosphoenol pyruvate (PEP) to oxaloacetate. GDH is present in the cytosol, chloroplast, and mitochondria [20] so making it possible for it to perform its metabolic integration functions. PEPCase recycles $\mathrm{CO}_{2}$ released during photorespiration thus minimizing carbon losses and enhancing carbon economy in higher plants [32]. PEP is the starting intermediate for the biosynthesis of try, phe, and tyr. In addition, pyruvate kinase could convert it to pyruvate which is the starting intermediate for the biosynthesis of val, leu, and ala. Oxaloacetate is the starting intermediate for the biosynthesis of ile, thr, asp, lys, and met. Because the relative concentrations of PEP and oxaloacetate depend on PEPCase activity, the abundance of the mRNA encoding the enzyme (Figure 1(b)) is important in the molecular integration of amino acid biosynthesis.

2) Isocitrate lyase: The Northern band population obtained using the cDNA probe for the mRNA encoding ICL were similar to those for PEPCase (Figure 1(b)) the difference being that their molecular weight was about $2.0 \mathrm{~kb}$ like the mRNAs encoding the ICL of other higher plants [33]-[35]. The mRNA encoding ICL was silenced in KN-treated peanut, partially silenced in NPKS-treated peanut, but was not silenced in control, and NPPK-treated peanuts (Figure 1(b)). The cDNA probe for ICL (Table 1) matched five times within the mRNA encoding the enzyme, three of which were plus/plus sequence homologies while two were minus/plus. These complex matches 
of the cDNA probe to the mRNA made for such tenacious in vitro binding that several high stringency washes of the nitrocellulose membranes $\left(65^{\circ} \mathrm{C}\right.$ for $\left.3-5 \mathrm{~h}\right)$ were done in order to clean-out loosely-bound probe molecules from the membranes. The crisscross binding in vivo between the GDH-synthesized RNA and the mRNA encoding the ICL assured liquefaction specificity of the mRNA silencing reaction. Isocitrate lyase is present in glyoxysomes and peroxisomes where it functions with chloroplasts and mitochondria [35] to initiate the glyoxylate cycle by catalyzing the cleavage of isocitrate to succinate and glyoxylate. GDH, by being present in mitochondria, chloroplast, and cytosol [20] is strategically located to regulate the abundance of the mRNA encoding ICL. Alpha-ketoglutarate, the intermediate which gives rise to pro, arg, his, glu, and gln is derived from isocitrate. Because the concentration of isocitrate is dependent on the activity of ICL, the abundance of the mRNA encoding the enzyme (Figure 1(b)) is important in the molecular integration of amino acid biosynthesis.

3) Malate synthase: The Northern band population (Figure $\mathbf{1}(\mathbf{d})$ ) obtained using the cDNA probe for the mRNA encoding MS showed that they were about $1.9 \mathrm{~kb}$ molecular weight similar to that of other higher plants [36] [37]. The mRNA encoding MS was silenced in the KN-treated peanut, partially silenced in the NPKS and NPPK-treated peanuts, but was not silenced in the control peanut (Figure 1(d)). The MS cDNA probe (Table 1) matched two times within the mRNA encoding the enzyme, the first match was plus/minus sequence homology while the other match was plus/plus. These complex matches of the cDNA probe to the MS mRNA made for tenacious in vitro binding that demanded several high stringency washes of the nitrocellulose membranes $\left(65^{\circ} \mathrm{C}\right.$ for 3 - 5 h) in order to clean-out the Northern membranes (Figure 1(d)). The crisscross binding in vivo between the GDH-synthesized RNA and the mRNA encoding the enzyme assured liquefaction specificity of the mRNA silencing reaction. The analytical advantage is that the molecule that induced the mRNA silencing was the molecule that was experimentally applied to demonstrate the abundance of the mRNA. Therefore, the Northern population of bands (Figure $\mathbf{1}(\mathrm{d})$ ) is the demonstration of the silencing of the mRNA encoding the enzyme. Malate synthase and isocitrate lyase participate in the reactions of the glyoxylate cycle which is responsible for the net conversion of two molecules of acetyl coenzyme A into succinate thereby bypassing the decarboxylation steps of the citric acid cycle. Malate synthase and isocitrate lyase are coordinately expressed and are active in germinating oil seeds just as they are in harvested seeds [34] thus confirming their regulation of isocitrate concentration in seeds.

4) Malate dehydrogenase: The Northern band population (Figure 1(f)) obtained using the cDNA probe for the mRNA encoding MDH showed that they were about $2.3 \mathrm{~kb}$ molecular weight similar to that of other higher plants [38] [39]. The mRNA encoding MDH was silenced in KN and NPKS-treated peanuts but was not silenced in control and NPPK-treated peanuts (Figure 1(f)). The MDH cDNA probe (Table 1) matched three times within the mRNA encoding the enzyme, the first match was plus/minus sequence homology, the second one was minus/plus, and the third was plus/plus. These complex matches of the cDNA probe to the MDH mRNA made for such tenacious in vitro binding in Northern hybridization that several high stringency washes of the nitrocellulose membranes ( $65^{\circ} \mathrm{C}$ for 4 - $5 \mathrm{~h}$ ) were done in order to clean-out the Northern membranes (Figure $\mathbf{1}(\mathbf{f})$ ). The practical advantage of the research procedure is that the molecule that induced the mRNA silencing was the molecule that was experimentally applied to demonstrate the abundance of the mRNA. Therefore, the differential Northern population of bands (Figure 1(f)) is the demonstration of the co-silencing of the mRNA encoding the enzyme. NADP-dependent malatedehydrogenase is present in the cytosol and mitochondria where it catalyzes the NADP ${ }^{+}$dependent conversion of oxaloacetate to malate. Oxaloacetate in mitochondria is the carbon skeleton for the synthesis of many essential amino acids including lysine, methionine, threonine, isoleucine; and the non-essential amino acids aspartic acid and asparagine.

5) Enolase: The Northern band population obtained using the cDNA probe for the mRNA encoding enolase were similar to those for PEPCase (Figure 1(b)) the difference being that their molecular weight was about $1.8 \mathrm{~kb}$ like the mRNAs encoding the enolase of other higher plants [40] [41]. The mRNA encoding the enzyme was not silenced in all the experimental peanut. The GDH-synthesized RNA that was homologous to the mRNA encoding for enolase (Table 1) had a plus/minus match with the mRNA. Enolase catalyzes the non-exergonic conversion of glycerate-2-phosphate to phosphoenolpyruvate, the only dehydration step in glycolysis.

6) NADP-dependent glyceraldehyde-3-phosphate dehydrogenase: The Northern band population obtained using the cDNA probe for the mRNA encoding GAPDH showed there was a family of three molecular weight bands of about $1.5 \mathrm{~kb}$ (Figure 2(a)) suggestive of the existence of isoforms of the enzyme [42] [43]. The mRNAs encoding the enzyme were silenced in control, and KN-treated peanuts, partially silenced in NPKS-treated peanut, but not silenced in NPPK-treated peanut. The GDH-synthesized RNA that was homologous to the mRNAs encoding GAPDH (Table 1) had a plus/plus match with the family of mRNAs. The differential abundance of the 
mRNAs displayed in the Northern blot (Figure 2(a)) represented in real time the mRNA silencing activity of the GDH-synthesized RNA because the Northern probe was the cDNA of the homologous RNA synthesized by GDH. In photosynthesis, NADP-GAPDH is at the intersection between glycolysis and Calvin Cycle because it slows down the rate of glycolysis leading to a pool of glyceraldehyde-3-phosphate, which is available to the Calvin Cycle for the assimilation of gaseous $\mathrm{CO}_{2}$ into carbohydrate synthesis.

7) Phosphoglycerate mutase: The Northern band population (Figure 2(b)) obtained using the cDNA probe for the mRNA encoding co-factor independent PGlycM showed that they were about $1.8 \mathrm{~kb}$ molecular weight similar to that of other higher plants [44] [45]. The mRNA encoding the enzyme was silenced in control peanut, incompletely silenced in KN and NPKS-treated peanuts, but not silenced in NPPK-treated peanut. The phosphoglycerate mutase cDNA probe (Table 1) matched one time (plus/minus) within the mRNA encoding the enzyme. Similar to the other Northern blots made with GDH-synthesized RNAs, the blot for the mRNA encoding PGlycM (Figure 2(b)) demonstrated visually the co-silencing activity of the homologous GDH-synthesized RNA. The single Northern band per experimental peanut (Figure 2(b)) suggested the monomeric structure of the enzyme similar to that of maize [44]. Glycerate-3-phosphate is the starting intermediate for the biosynthesis of cys, ser, and gly. Because the concentration of glycerate-3-phosphate is dependent on PGlycM activity, the abundance of the mRNA (Figure 2(b)) encoding the enzyme is important in the molecular integration of amino acid biosynthesis.

\subsection{Integration and Discrimination of Glycolysis, Citric and Glyoxylic Acid Cycles}

There is a complex network of sequence homologies between the mRNAs encoding the enzymes that catalyze the non-exergonic reactions of glycolysis, citric and glyoxylic acid cycles. The Northern bands were the results of the integration-discrimination silencing reactions of the mRNAs. The mRNA sequence similarities were demonstrated by the differences and similarities in the Northern band patterns (Figure 1 and Figure 2) and as revealed by the nucleotide sequences of the GDH-synthesized RNA probes. Multiple sequence repeats are the exclusive structural characteristic of the GDH-synthesized RNA because of the binomial arrangement of the subunit polypeptides inside the GDH hexamers [46]. The sequence repeats are responsible for the unusually high binding specificity of the GDH-synthesized RNA for their homologous mRNA targets. GDH-synthesized RNAs silence the mRNAs that are homologous to them [19].

GDH-synthesized RNA probe 53M (Table 1) that shared sequence homology with the mRNA encoding PEPCase (glycolysis) also sheared plus/plus sequence homology with the GDH-synthesized RNA probe 96K homologous to the mRNA encoding MS (glyoxylate cycle); five folds plus/minus sequence homologies with the GDH-synthesized RNA probe 15F homologous to the mRNA encoding MDH (citric acid cycle);plus/plus sequence homology with the GDH-synthesized RNA probe 10E homologous to the mRNA encoding PGlycM (glycolysis);and plus/plus sequence homology with the GDH-synthesized RNA probe 15D homologous to the mRNA encoding ICL (glyoxylate cycle).Therefore a single RNA sequence synthesized by GDH tenaciously linked glycolysis, citric and glyoxylic acid cycles at the mRNA level. Some of the cross talks coordinated by the signal molecules (probes) 53M, 96K, 15F, 10E, and 15D are graphically depicted (Figure 3). The sequential metabolic permutations revolving around the mRNA encoding PEPCase may be due to the importance of the enzyme in controlling carbon fluxes through glycolysis, gluconeogenesis, and citric acid cycle [41]. This meant that within the metabolic order, the five mRNAs could not be knocked out simultaneously under any applied mineral ion regimen. The five mRNAs were co-silenced in glycolysis, glyoxylic and citric acid cycles of KNtreated peanut, but differentially silenced in NPKS-treated peanut (Figure 1 and Figure 2).

GDH-synthesized RNA probe 15D that shared sequence homology with the mRNA encoding ICL sheared plus/plus sequence homology with the GDH-synthesized RNA probe $\mathbf{9 6 K}$ homologous to the mRNA encoding MS (glyoxylic acid cycle).Therefore, the abundances of the mRNAs encoding the enzymes are jointly regulated thus further confirming the co-regulation of the expression of the two enzymes [34]. GDH-synthesized RNA probe 15D that shared sequence homology with the mRNA encoding ICL(glyoxylate cycle) also sheared three folds plus/plus sequence homology with the GDH-synthesized RNA probe 10E homologous to the mRNA encoding PGlycM; and plus/minus sequence homology with the GDH-synthesized RNA probe 60F homologous to the mRNA encoding enolase. This is a reciprocal regulation of the mRNAs which are homologous to the same GDH-synthesized RNA so that at least one in the group of mRNAs could not be knocked out with the other three. Some of the cross talks coordinated by the signal molecules (probes) 15D, 96K, 10E, and 60F are graphically depicted (Figure 3). This made for maximum efficient utilization of glycolytic, glyoxylic 


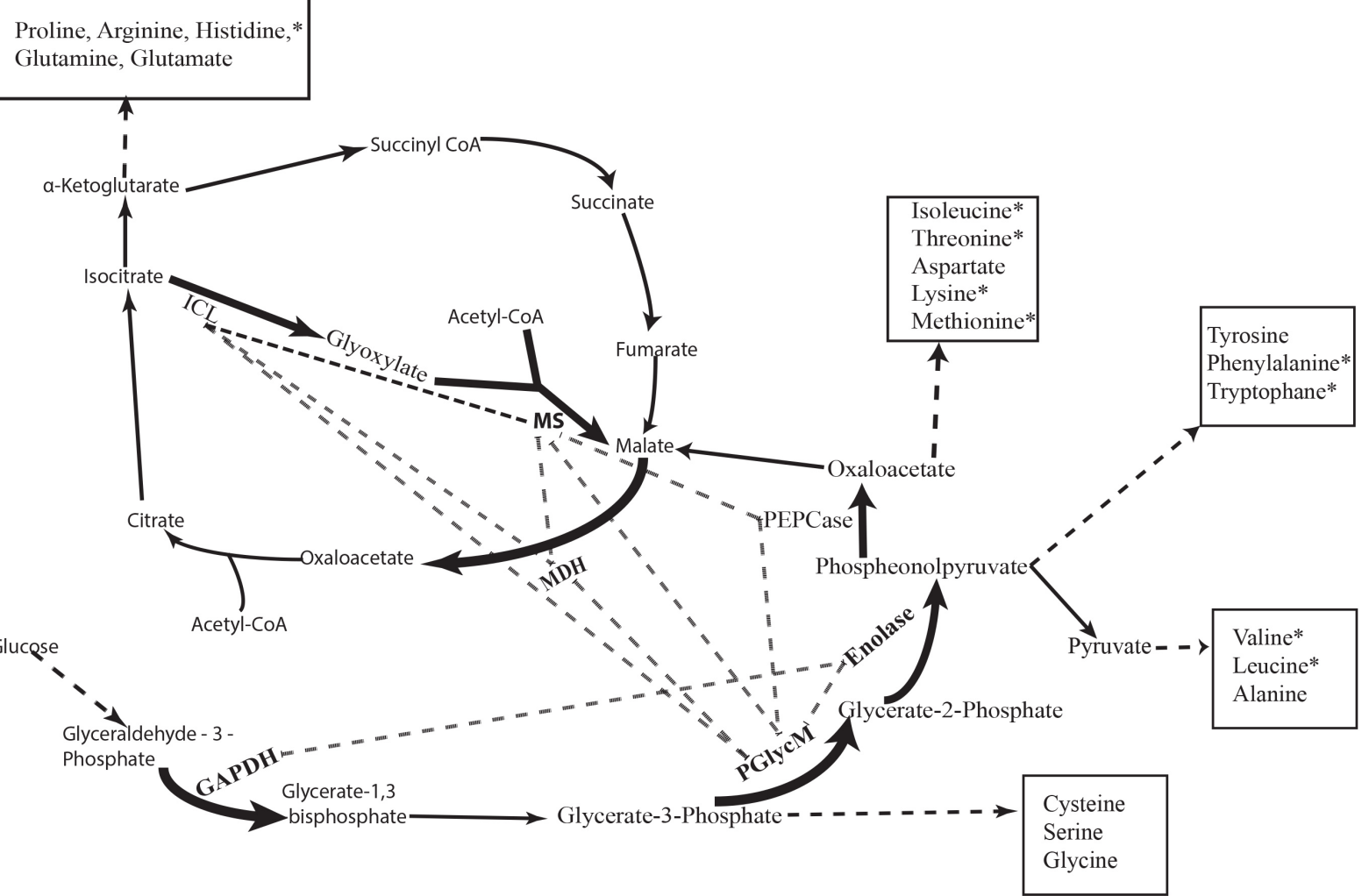

Figure 3. Anti-parallel alignment at the mRNA level between glycolysis and glyoxylic-citric acid cycle: Illustration of the "spoke and hub" cross-talks (dashed lines without arrow heads) involving the common homologous sequences in the mRNAs encoding isocitrate lyase (ICL), malate synthase (MS), malate dehydrogenase (MDH), phosphoenol pyruvate carboxylase (PEPCase), enolase, phosphoglycero mutase (PGlycM), and glyceraldehyde-3-phosphate dehydrogenase (GAPDH). The asterisked amino acids are essential amino acids. Bold arrows indicate the non-exergonic reaction steps.

and citric acid cycle intermediates for the $\alpha$-ketoglutarate, and oxaloacetate groups of amino acid biosynthesis. The mRNAs encoding the four enzymes were differentially-silenced in the glycolysis and glyoxylate cycle of KN, NPKS-treated, and control peanuts, but were not silenced in the NPPK-treated peanut (Figure 1 and Figure 2).

Reciprocal regulation of glycolysis, glyoxylic and citric acid cycles was further enforced by the GDH-synthesized RNA probe that is homologous to the mRNA encoding MDH. The RNA probe $15 F$ that shared sequence homology with the mRNA encoding MDH (citric acid cycle) sheared four folds of plus/minus sequence homologies with the GDH-synthesized RNA probe 96K homologous to the mRNA encoding MS (glyoxylic acid cycle); six folds of plus/minus sequence homologies with the GDH-synthesized RNA probe 15D homologous to the mRNA encoding ICL (glyoxylate cycle), one plus/plus sequence homology and six folds of plus/minus sequence homologies with the GDH-synthesized RNA probe 10E homologous to the mRNA encoding PGlycM (glycolysis), and four folds of plus/plus sequence homologies with the GDH-synthesized RNA probe 60F homologous to the mRNA encoding enolase. These sequential reciprocal cross talks meant that at least one of the mRNAs could not suffer demise with the others. This again ensured efficient utilization of metabolic intermediates for the biosynthesis of the oxaloacetate group containing four EAAs. Some of the cross talks coordinated by the signal molecule $15 \mathrm{~F}$ that is homologous to the mRNA encoding MDH in cooperation with probes $96 \mathrm{~K}, 15 \mathrm{D}, 10 \mathrm{E}$, and $60 \mathrm{Fare}$ graphically depicted (Figure 3) to highlight the central importance of MDH, an enzyme catalyzing a non-exergonic reaction, in the big picture integration and discrimination of glycolysis, glyoxylic and citric acid cycles. This spider web-like coordination by the GDH-synthesized RNAs (Figure 3) that are homologous to the mRNAs encoding MDH, MS, ICL, PGlycM, and enolase provided an all-round protection so that all five of them could not suffer demise under any applied mineral ion regimen. This is the molecular explanation of location-induced variability of the amino acid compositions of peanut [47]. The mRNAs encoding the five enzymes were diffe- 
rentially silenced in all the experimental peanuts (Figure 1 and Figure 2).

GDH-synthesized RNA probe $\mathbf{9 6 K}$ that shared sequence homology with the mRNA encoding MS (glyoxylate cycle) also sheared plus/plus sequence homology with the GDH-synthesized RNA probe 10E homologous to the mRNA encoding PGlycM (glycolysis). GDH-synthesized RNA probe $\mathbf{5 6 N}$ that shared sequence homology with the mRNA encoding GAPDH (glycolysis) also sheared plus/plus sequence homology with the GDH-synthesized RNA probe 60F homologous to the mRNA encoding enolase (glycolysis). The mRNAs encoding the two enzymes were coordinately silenced in the KN, and NPKS-treated peanuts (Figure 1 and Figure 2). GDH-synthesized RNA probe 10E that shared sequence homology with the mRNA encoding PGlycM (glycolysis) also sheared plus/minus sequence homology with the GDH-synthesized RNA probe 60F homologous to the mRNA encoding enolase (glycolysis). Based on the large numbers of sequence homologies between the mRNA encoding MDH and the mRNAs encoding PGlycM, enolase, PEPCase, ICL, and MS, the big picture over-view (Figure 3) shows the operation of a biochemical spoke and hub network mechanism with MDH as the hub for integrating the biosynthesis of amino acid groups. The spoke and hub network of homologous sequences was also made visible by the anti-parallel alignment between glycolysis and citric-glyoxylic acid cycles.

The cob web-like cross connections between glycolysis, glyoxylic and citric acid metabolic pathways at the mRNA level (Figure 3) introduce the concept of probability or likelihood for metabolites to flow in one or alternative directions in peanuts treated with mineral ions.

\subsection{Spatial Permutation of Glycolysis, Glyoxylic and Citric Acid Cycles}

GDH-synthesized RNAs are statistical in nature, their primary structure being dependent on the binomial subunit compositions of the GDH isoenzymes [17] [46]. Therefore several probabilities arise under a prevailing mineral nutrient combination/concentration for the GDH-synthesized RNA to reprogram the mRNA abundances in glycolysis, citric and glyoxylic acid cycles and consequently, the rates of biosynthesis of amino acids and proteins. The rearrangement of the sequence of metabolism in response to the prevailing mineral ions in order to optimize amino acid biosynthesis can best be approached by permuting the three pathways guided by the "musical chairs game play”: enzyme systems that were not silenced, partially silenced, and fully silenced (Table 2) by GDH-synthesized RNAs per mineral ion environment, and limited to the seven non-exergonic reaction steps in the three metabolic pathways (chairs) affected. Digital (UN-SCAN-IT) quantitation of the Northern bands (Figure 1 and Figure 2) showed that whereas some mRNAs were fully silenced (knocked out), the majority were partially silenced (knocked down) to varying extents ranging from $25 \%, 50 \%$, and $75 \%$ as depicted in Table 2. The number of permutations varied widely: control peanut produced 105; KN-treated peanut produced 420; NPPK-treated peanut produced 42; NPKS-treated peanut produced 420 permutations. This means for example that there are 42 probable alternative metabolic and amino acid yield responses of peanut to applied NPPK mineral nutrient combination. Therefore, there were many probable rearrangements of peanut glycolysis, citric and glyoxylic acid cycles in response to any mineral nutrient regimen. The living outcomes of the sequential and spatial integration and discrimination permutations at the mRNA level are depicted by the Northern blot images (Figure 1 and Figure 2). This explains the lack of agreement about the peanut amino acid composition responses to environmental factors, growing seasons, and planting date [48].

Table 2. Integration and discrimination of glycolysis, citric-glyoxylic acid cycles at the mRNA level by GDH-synthesized RNA in response to stoichiometric mineral ion treatment of peanut. ${ }^{\text {a }}$

\begin{tabular}{|c|c|c|c|c|c|c|c|}
\hline \multirow{2}{*}{ Treatments } & \multicolumn{7}{|c|}{ mRNAs Encoding Enzymes that Catalyze Non-exergonic Reaction Steps in Glycolysis and Citric-Glyoxylic Acid Cycle } \\
\hline & GAPDH & PGlycM & ICL & PEPCase & Enolase & MS & $\mathrm{MDH}$ \\
\hline Control & ---- & ---- & ++++ & +--- & ++++ & +++ & +++ \\
\hline $\mathrm{KN}$ & ---- & +--- & +--- & ++-- & ++++ & ---- & ---- \\
\hline NPKS & ++-- & ++-- & +++- & ++++ & ++++ & ++-- & ---- \\
\hline NPPK & ++++ & ++++ & ++++ & ++-- & ++++ & +++- & ++++ \\
\hline
\end{tabular}

${ }^{\mathrm{a}} \mathrm{Key}:----$ is $>90 \%$ silenced mRNA; +--- is up to $75 \%$ silenced mRNA; ++-- is $\sim 50 \%$ silenced $\mathrm{mRNA} ;+++-$ is $<25 \%$ silenced mRNA determined by mRNA band digitalization. 


\subsection{Molecular Regulation of Total and Protein-Bounded Amino Acid Compositions}

Because of the coordinate and differential silencing of the mRNAs encoding ICL and MS, wherever the abundances (Figure 1(b) and Figure 1(d)) of these mRNAs were high (control, and NPPK-treated peanuts) the concentrations of the $\alpha$-ketoglutarate group of amino acids (glu, gln, arg, pro, his) were very low but the concentrations of the oxaloacetate group of amino acids (asp, lys, met, thr, ile) were very high and maximized (Table 3). Furthermore, wherever the abundances of the two mRNAs encoding these enzymes were very low (KN-treated peanut) the concentrations of the $\alpha$-ketoglutarate group of amino acids were about equal to the concentrations of the oxaloacetate group of amino acids (Table 3). Conversely, wherever the abundances of the mRNAs encoding

Table 3. Free amino acids and protein-bounded essential amino acids of peanut seeds of control, and mineral salts-treated peanuts.

\begin{tabular}{|c|c|c|c|c|c|c|c|c|}
\hline \multirow{2}{*}{$\begin{array}{l}\text { Amino Acid } \\
\text { Groups } \\
\text { Treatments }^{\mathrm{a}}\end{array}$} & \multicolumn{4}{|c|}{$\begin{array}{c}\text { Total Amino Acids } \\
\text { (free plus protein-bounded amino acids) (mg/g peanut) }\end{array}$} & \multicolumn{4}{|c|}{$\begin{array}{l}\text { Protein-bounded essential amino acids } \\
\text { (mg/g peanut) }\end{array}$} \\
\hline & Control & $\mathrm{KN}$ & NPKS & NPPK & Control & $\mathrm{KN}$ & NPKS & NPPK \\
\hline \multicolumn{9}{|c|}{ Alpha-ketoglutarate Group } \\
\hline Glutamate & 2.36 & 0.0 & 22.72 & 1.01 & & & & \\
\hline Arginine & 0.70 & 0.0 & 0.79 & 1.82 & & & & \\
\hline Proline & 3.81 & 17.58 & 1.12 & 1.58 & & & & \\
\hline Histidine & 0.0 & 0.0 & 1.10 & 1.05 & 0.0 & 0.0 & 1.10 & 1.05 \\
\hline SUB TOTAL & 6.87 & 17.58 & 22.73 & 5.45 & 0.0 & 0.0 & 1.10 & 1.05 \\
\hline \multicolumn{9}{|c|}{ Oxaloacetate Group } \\
\hline Aspartate & 4.27 & 0.0 & 1.20 & 2.96 & & & & \\
\hline Lysine & 4.16 & 3.23 & 1.95 & 6.25 & 2.68 & 2.52 & 0.89 & 2.52 \\
\hline Methionine & 12.55 & 3.11 & 6.15 & 2.87 & 3.66 & 3.11 & 3.20 & 2.87 \\
\hline Threonine & 2.75 & 2.13 & 3.99 & 7.24 & 0.0 & 2.13 & 3.99 & 3.65 \\
\hline Isoleucine & 5.11 & 8.19 & 5.20 & 9.71 & 2.89 & 8.19 & 5.20 & 7.26 \\
\hline SUB TOTAL & 28.84 & 16.66 & 18.49 & 29.03 & 9.23 & 13.82 & 13.28 & 16.31 \\
\hline \multicolumn{9}{|c|}{ Phosphoenolpyruvate Group } \\
\hline Tyrosine & 1.13 & 1.14 & 5.94 & & & & & \\
\hline Phenylalanine & 5.88 & 3.61 & 4.41 & 5.54 & 0.91 & 0.87 & 3.39 & 2.38 \\
\hline SUB TOTAL & 7.01 & 5.10 & 10.35 & 6.03 & 0.91 & 0.87 & 3.39 & 2.38 \\
\hline \multicolumn{9}{|c|}{ Pyruvate Group } \\
\hline Leucine & 5.94 & 3.64 & 3.45 & 18.56 & 2.33 & 2.50 & 3.45 & 10.98 \\
\hline Valine & 3.19 & 2.81 & 5.83 & 2.65 & 3.19 & 2.81 & 3.58 & 2.65 \\
\hline Alanine & 7.61 & 7.30 & 0.0 & 0.59 & & & & \\
\hline SUB TOTAL & 16.74 & 13.75 & 9.28 & 21.80 & 5.52 & 5.31 & 7.03 & 13.63 \\
\hline \multicolumn{9}{|c|}{ Glycerate-3-phosphate Group } \\
\hline Cysteine & 3.96 & 2.95 & 0.84 & 3.74 & & & & \\
\hline Serine & 0.0 & 0.0 & 0.0 & 0.0 & & & & \\
\hline Glycine & 0.0 & 0.0 & 0.0 & 0.0 & & & & \\
\hline SUB-TOTAL & 3.96 & 2.95 & 1.14 & 4.07 & & & & \\
\hline TOTALs & 63.42 & 56.04 & 64.99 & 66.38 & 15.66 & 20.00 & 24.80 & 33.37 \\
\hline
\end{tabular}

Notes: a Treatments NPKS was $1 \mathrm{~L}$ of combined $\mathrm{NH}_{4} \mathrm{Cl}(25 \mathrm{mM}), \mathrm{Na}_{3} \mathrm{PO}_{4}(20 \mathrm{mM}), \mathrm{Na}_{2} \mathrm{SO}_{4}(50 \mathrm{mM})$, and $\mathrm{KCl}$ (4 mM) solution; NPPK was $1 \mathrm{~L}$ of combined $\mathrm{NH}_{4} \mathrm{Cl}(25 \mathrm{mM}), \mathrm{Na}_{3} \mathrm{PO}_{4}(40 \mathrm{mM})$ and $\mathrm{KCl}(4 \mathrm{mM})$ solution; $\mathrm{KN}$ was $1 \mathrm{~L}$ of combined $\mathrm{NH}_{4} \mathrm{Cl}(25 \mathrm{mM})$ and $\mathrm{KCl}(4 \mathrm{mM}) \mathrm{solution}$. 
these enzymes decreased to about 50\% (NPKS-treated peanut) the concentrations of the $\alpha$-ketoglutarate group of amino acids were very high and maximized but the concentrations of the oxaloacetate group of amino acids were low (Table 3). Therefore, in the integration of citric and glyoxylic acid cycles by GDH-synthesized RNA, some of the cross-talks between the mRNAs encoding ICL and MS were overridden. Coordinate regulation of the expression of the two mRNAs had been described [34] but co-silencing was not described.

The abundance of the mRNA (Figure 1(f)) encoding MDH further consolidated the biosynthesis of the oxaloacetate group of amino acids because in control and NPPK-treated peanuts with high abundances of the mRNA encoding $\mathrm{MDH}$, the oxaloacetate group of amino acids were up to $70 \%$ higher in concentration than in the KN and NPKS-treated peanuts with severely diminished abundances of the mRNA encoding MDH.

Therefore permutation of citric and glyoxylic acid cycles at the mRNA level reciprocally regulated the biosynthesis of the $\alpha$-ketoglutarate and oxaloacetate groups of amino acids. Molecular regulation of amino acid biosynthesis in plants had been limited to studies on enzyme activities [4].

The concentrations of the glycerate-3-phosphate group of amino acids were dependent on the permutation of the mRNAs encoding GAPDH (Figure 2(a)), PGlycM (Figure 2(b)), enolase, and ICL (Figure 1(a)) thus involving the integration and discrimination of glycolysis, citric and glyoxylic acid cycles by the GDH-synthesized RNAs. Therefore, the biosynthesis of the glycerate-3-phosphate group of amino acids competed with the biosynthesis of all the other amino acids; the competition resulted to the very low concentrations of cysteine, serine, and glycine irrespective of the mineral ion treatment of the peanut (Table 2). Analyses of total amino acid contents of 16 varieties of peanuts showed that ser, gly, and cys together were the lowest in concentration [49].

The permutation of the mRNAs encoding PEPCase (Figure 1(b)) and MDH (Figure 1(f), and Figure 3) reciprocally regulated the concentrations of the PEP and pyruvate groups of amino acids (Table 3). When the abundances of the two mRNAs were very high (NPPK-treated peanut), the pyruvate group of amino acids was very high in concentration but the PEP group was very low. Conversely, when the abundance of the mRNA encoding PEPCase was very high (NPKS-treated peanut) but the mRNA encoding MDH was very low (Figure $1(f))$ the concentration of the pyruvate group of amino acids was low and the concentration of the PEP group of amino acids was high and maximized (Table 3). Therefore, the concentrations of amino acid groups are dependent on the abundance of more than a single mRNA. These are new insights into the integration and discrimination regulation of glycolysis, citric and glyoxylic acid cycles at the mRNA level by GDH-synthesized RNA with reference to amino acid biosynthesis.

KN-treated peanut displayed the lowest abundances of the mRNAs encoding the seven non-exergonic enzymes in glycolysis, citric and glyoxylic acid cycles (Figure 1 and Figure 2). This explains the lowest content of total amino acids (free plus protein-bounded) of the KN-treated peanut (Table 3). This is further support that many mRNAs undergo statistical integration and discrimination by GDH-synthesized RNAs in the biosynthesis of groups of amino acids.

\subsection{Molecular Regulation of Essential Amino Acid Biosynthesis}

The richest concentration of EAAs is the oxaloacetate group. Therefore, the treatments that induced high abundances of the mRNAs encoding ICL and MS (glyoxylate cycle enzymes) and of MDH should produce the highest yield of the protein-bounded EAAs. Accordingly, the highest concentrations of protein-bounded amino acids were synthesized by the NPPK-treated peanut (Table 3). The integration of high abundances of the mRNAs encoding ICL, MS, and MDH by GDH-synthesized RNAs induced the highest biosynthesis of the EAAs in peanuts. Up to $50 \%$ of the EAAs synthesized by the NPPK-treated peanut was protein-bounded, whereas only about $25 \%$ was protein-bounded in control peanut. Therefore, the non-exergonic reaction steps in glycolysis and citricglyoxylic acid cycle constitute the biochemical mechanisms that improve the nutritious EAA quality of plant proteins. This is a new and simple plant sciences-based biotechnology compared with earlier ones [2] [17] because it doubles the biosynthesis of EAAs at the whole plant level. An advantage of this biotechnology is that it could be limited resource-farmer friendly, empowering family-owned gardens to produce EAA nutritious food crops. Essential amino acid-rich food crops project naturally dove-tails to agricultural extension research activities for the benefits of those communities that are disabled by protein-nitrogen undernutrition [21]-[23].

The biosynthesis of the EAAs lys, thr, met, and ile in higher plants had been described as being regulated by end-product feedback inhibition of branch-point enzymes [11]. Research approaches that increased the free EAA compositions of food crops resulted to leaching losses of the amino acids during cooking and other pro- 
cessing [11] [50]. An advantage of the spoke and hub mechanism (Figure 3) involving the molecular integration of glycolysis and citric-glyoxylic acid cycles so as to optimize the EAAs is that the amino acids are efficiently incorporated into proteins. Therefore, although glycolysis and citric acid cycle were the earliest metabolic pathways studied, they still remain relevant to nutritional issues faced in modern biology. Plants provide the bulk of the proteins in food and feed. But plant proteins vary greatly in their balance of EAAs which cannot be synthesized in the human body, deficiencies of which often leading to protein undernutrition [3] [51]. Since peanut formulations are being prescribed as nutritional therapies and supplements for the management of kwashiorkor by medical doctors [23] and humanitarian agencies operating in several hunger-ravaged zones of Africa, the EAA-rich peanuts could help to restore improved health faster.

\subsection{The Biotechnology}

Mineral salts mixed in stoichiometric ratio was the biotechnology that unleashed the spoke and hub responses on the glycolytic, citric-glyoxylic acid cycles (Figure 3) via the RNA synthetic activity of GDH. The applied mineral ion compositions were based on the model molar combinations [17] [26] that activate peanut biomass metabolism.Because chemical reactants, including mineral nutrient ions and their target sites, interact according to stoichiometric ratios, it is biochemically beneficial to plants that fertilizer nutrients be applied in stoichiometric ratios rather than in weight ratios when determining the responses of metabolism to mineral ion concentrations. It has been repeatedly demonstrated that stoichiometric mineral nutrient mixes doubled the dry matter yields of crop plants [16] [17]. Crop yield doubling biotechnology [16]-[20] is a process for increasing food production and improving its nutritious quality without compromising environmental safety [24]. The stoichiometric mineral salt mixes via the crop yield doubling biotechnology doubled the nutritious EAA (Table 3) and crude protein contents as well as the seed yields (Table 4). Seed yield was doubled with respect to the NPPK-treated peanut (Table 4) but not the control untreated peanut because the NPPK-treated peanut housed the control GDH. The control untreated peanut was just the control crop experimental condition but it did not house the control GDH. This is an important reason to differentiate the control crop from the control GDH in all research projects on GDH. The control crop does not necessarily equate to the control GDH [20]. Doubling of crop yield is achieved through the integration and discrimination (permutation) of glycolytic, fatty acid, nucleotide, cellulose, and photosynthetic pathways by GDH-synthesized RNA [17].

Although peanut metabolism is adapted to variations in the terrestrial ecosystems [18], only narrow ranges of mineral ion concentrations can support the crop to produce nutritious constituents [16]-[18]. A changing global climate with attendant adverse changes in soil organic matter and mineral nutrients [15] make it mandatory that crucial relevant research should be conducted to identify the optimal conditions for crops to produce nutritious constituents as food and feed. Current agronomic production conditions for peanut [52] are similar to the control, and $\mathrm{KN}$-treated peanuts (Table 3), and they are primarily designed to achieve great yields of vegetable oil for industrial purposes, but are deficient in protein-bounded EAA. Control, and KN-treated peanuts had low crude protein contents (26.17 and $25.26 \mathrm{~g} / 100 \mathrm{~g}$ respectively) compared with NPKS, and NPPK-treated peanuts (31.89 and $31.72 \mathrm{~g} / 100 \mathrm{~g}$ respectively). Therefore, when the protein-bounded EAA concentration is balanced, maximized, and doubled as in the stoichiometric NPPK-treated peanut, the crude protein content is equally maximized. Conversely, when the protein-bounded EAA concentration is minimized and halved as in the control peanut, the crude protein content is similarly minimized. It is important to conduct relevant research to identify the conducive stoichiometric mineral nutrient environmental conditions for crop plants to produce optimized EAA compositions and other nutritious constituents.

Table 4. Responses of peanut seed and protein yields to stoichiometric combinations of mineral ions.

\begin{tabular}{ccc}
\hline Treatments & Crude Protein (g/100 g seed) & Unshelled seed (kg/box) \\
\hline KN & 25.26 & $1.90 \pm 0.14$ \\
NPKS & 31.89 & $1.86 \pm 0.11$ \\
Control (untreated) & 26.17 & $1.48 \pm 0.07$ \\
NPPK & 31.72 & $0.86 \pm 0.06$ \\
\hline
\end{tabular}




\section{Conclusion}

There is no simple biotechnology for improving the EAA composition of plant proteins. The aim was to integratediscriminate glycolysis and citric-glyoxylic acid cycle in order to optimize the biosynthesis of EAAs in food crops. Integration of diverse metabolic pathways at the mRNA level by glutamate dehydrogenase (GDH)-synthesized RNA is a common biotechnological approach for doubling the nutritious compositions of plants. Peanuts were planted in plots and treated with mineral ions mixed according to their molar ratios. Protein-bounded and free amino acids of mature peanut seeds were determined by HPLC. GDH-synthesized RNA probes homologous to the mRNAs encoding glyceraldehyde 3-phosphate dehydrogenase (GAPDH), phosphoglycerate mutase (PGlycM), phosphoenolpyruvate carboxylase (PEPCase), enolase in glycolysis; malate dehydrogenase (MDH), isocitrate lyase (ICL), malate synthase (MS) in citric-glyoxylic acid cycles were prepared from mature peanut seeds using restriction fragment double differential display PCR amplification method of Display Systems Biotech, CA, USA. Northern hybridization of peanut total RNA showed that the mRNAs encoding PGlycM, PEPCase, MDH, and MS shared extensive sequence homologies that promoted a network of cross-talks, resulting to co-differential silencing of the mRNAs thereby integrating glycolysis and citric-glyoxylic acid cycle in the NPPK-treated peanut, but discriminated glycolysis from citric-glyoxylic acid cycle in control and $\mathrm{KN}$-treated peanuts. Because of the coordinate and differential silencing of the mRNAs encoding ICL and MS, wherever the abundances of these mRNAs were high (control, and NPPK-treated peanuts) the concentrations of the $\alpha$-ketoglutarate group of amino acids (glu, gln, arg, pro, his) were very low but the concentrations of the oxaloacetate group of amino acids (asp, lys, met, thr, ile) were very high and maximized. So, the inactivation of the glyoxylate cycle enzymes (ICL and MS) led to increased biosynthesis of his, pro, arg, glu, and gln. When the abundances of the mRNAs encoding PEPCase and MDH were very high (NPPK-treated peanut), the pyruvate group of amino acids (leu, val, ala) was very high in concentration, but the PEP group (tyr, phe, try) was very low. Conversely, when the abundance of the mRNA encoding PEPCase was very high (NPKS-treated peanut) but the mRNA encoding MDH was very low, the concentration of the pyruvate group was low and the concentration of the PEP group of amino acids was high and maximized. The non-exergonic reaction steps in glycolysis and citric-glyoxylic acid cycle constitute the biochemical mechanisms that improve the nutritious EAA quality of plant proteins. Mineral ions mixed in stoichiometric ratios induced the cross-talk responses between the glycolytic, citric/glyoxylic acid cycles via the activity of GDH.

\section{Acknowledgements}

The project was funded by NIFA-USDA-Allen fund made to Prairie View A\&M University. The Institutional Review Board of the University approved and monitored the project.

\section{Competing Financial Interests}

The authors declare no competing financial interests.

\section{References}

[1] Ory, R.L. (1986) Plant Proteins: Applications, Biological Effects, and Chemistry. American Chemical Society Symposium Series 312, ACS Publishers, Washington DC. http://dx.doi.org/10.1021/bk-1986-0312

[2] Osuji, G.O. and Cuero, R.G. (1992) N-Carboxymethylchitosan Enhancement of the Storage Protein Contents of Maize Seeds (Zea mays L.). Food Biotechnology, 6, 105-126. http://dx.doi.org/10.1080/08905439209549826

[3] Wu, G. (2010) Functional Amino Acids in Growth, Reproduction, and Health. Advances in Nutrition, 1, 31-37. http://dx.doi.org/10.3945/an.110.1008

[4] Singh, B.K. and Matthews, B.F. (1994) Molecular Regulation of Amino Acid Biosynthesis in Plants. Amino Acids, 7, 165-174. http://dx.doi.org/10.1007/BF00814158

[5] Yokogoshi, H. and Yoshida, A. (1980) Effects of Supplementation and Depletion of a Single Essential Amino Acid on Hepatic Polyribosome Profile in Rats. Journal of Nutrition, 110, 375-380.

[6] Wu, G., Bazer, F.W., Cudd, T.A., Meininger, C.J. and Spencer, T.E. (2004) Maternal Nutrition and Fetal Development. Journal of Nutrition, 134, 2169-2172.

[7] Suryawan, A., O’Connor, P.M.J., Bush, J.A., Nguyen, H.V. and Davis, T.A. (2009) Differential Regulation of Protein Synthesis by Amino Acids and Insulin in Peripheral and Visceral Tissues of Neonatal Pigs. Amino Acids, 37, 97-104. 
http://dx.doi.org/10.1007/s00726-008-0149-z

[8] Planchet, E. and Limami, A.M. (2015) Amino Acid Synthesis under Abiotic Stress. In: D’Mello, J.P.F., Ed., Amino Acids in Higher Plants, CABI Publishers, Oxfordshire and Boston, 262-276. http://dx.doi.org/10.1079/9781780642635.0262

[9] St Jeor, S., Howard, B. and Prewitt, E. (2001) Dietary Protein and Weight Reduction: A Statement from Healthcare Professionals from the Nutrition Committee of the Council on Nutrition, Physical Activity, and Metabolism of the American Heart Association. Circulation, 104, 1869-1874. http://dx.doi.org/10.1161/hc4001.096152

[10] Mosse, J. and Baudet, T. (1983) Crude Protein Content and Amino Acid Composition of Seeds: Variability and Correlations. Plant Foods for Human Nutrition, 32, 225-245. http://dx.doi.org/10.1007/BF01091188

[11] Matthews, B.F. and Hughes, C.A. (1993) Nutritional Improvement of the Aspartate Family of Amino Acids in Edible Crop Plants. Amino Acids, 4, 21-34. http://dx.doi.org/10.1007/BF00805798

[12] Dudley, J.W., Dijkhuizen, A., Paul, C., Coates, S.T. and Rocheford, T.R. (2004) Effects of Random Mating on MarkerQTL Associations in the Cross of the Illinois High Protein x Illinois Low Protein Maize Strains. Crop Science, 44, 1419-1428. http://dx.doi.org/10.2135/cropsci2004.1419

[13] Fraire-Velazquez, S. and Balderas-Hernandez, V.E. (2013) Abiotic Stress in Plants and Metabolic Responses. In: Vahdati, K. and Leslie, K., Eds., Abiotic Stress-Plant Responses and Applications in Agriculture, In Tech Publishers, Croatia, 25-48. http://dx.doi.org/10.5772/54859

[14] D’Mello, J.P.F. (2012) Emergence of a New Momentum. In: D’Mello, J.P.F., Eds., Amino Acids in Human Nutrition and Health, CABI Publishers, Oxfordshire and Boston, 497-524.

[15] Fageria, N.K. (2012) Role of Soil Organic Matter in Maintaining Sustainability of Cropping Systems. Communications in Soil Science and Plant Analysis, 43, 2063-2113. http://dx.doi.org/10.1080/00103624.2012.697234

[16] Osuji, G.O., Brown, T.K. and South, S.M. (2010) Optimized Fat and Cellulosic Biomass Accumulation in Peanut through Biotechnology. International Journal Biotechnology Biochemistry, 3, 455-476.

[17] Osuji, G.O., Brown, T.K., South, S.M., Duncan, J.C. and Johnson, D. (2011) Doubling of Crop Yield through Permutation of Metabolic Pathways. Advances Bioscience Biotechnology, 2, 364-379. http://dx.doi.org/10.4236/abb.2011.25054

[18] Osuji, G.O., Brown, T.K., South, S.M., Johnson, D. and Hyllam, S. (2012) Molecular Modeling of Metabolism for Allergen-Free Low Linoleic Acid Peanuts. Biotechnology and Applied Biochemistry, 168, 805-823. http://dx.doi.org/10.1007/s12010-012-9821-6

[19] Osuji, G.O., Brown, T.K. and South, S.M. (2008) Discovery of the RNA Synthetic Activity of GDH and Its Application in Drug Metabolism Research. The Open Drug Metabolism Journal, 2, 1-13. http://dx.doi.org/10.2174/1874073100802010001

[20] Osuji, G.O. and Madu, W.C. (2015) Glutamate Dehydrogenase. In: D’Mello, J.P.F., Eds., Amino Acids in Higher Plants, CABI Publishers, Oxfordshire and Boston, 1-29. http://dx.doi.org/10.1079/9781780642635.0001

[21] Fletcher, S.M. (2009) Evaluation and Results Report on the National Peanut Board's Domestic Peanut Market Program 1st Quarter 2005-3rd Quarter 2009.

[22] Putnam, D.H., Oplinger, E.S., Teynor, T.M., Oelke, E.A., Kelling, K.A. and Doll, J.D. (1991) Peanut. Alternative Field Crop Manual. http://www.hort.purdue.edu/newcrop/afcm/peanut.html (Accessed December 3, 2015)

[23] Doctors without Borders/Medicines San Frontieres (2012) http://www.doctorswithoutborders.org/news/issue.cfm?id=2396.

[24] Beddington, J. (2010) Food Security: Contributions from Science to a New and Greener Revolution. Philosophical Transactions of the Royal Society B, 365, 61-73. http://dx.doi.org/10.1098/rstb.2009.0201

[25] Armenta, J.M., Cortes, D.F., Pisciotta, J.M., Shuman, J.L., Blakeslee, K., et al. (2010) A Sensitive and Rapid Method for Amino Acid Quantitation in Malaria Biological Samples Using AccQ.Tag UPLC-ESI-MS-MS with Multiple Reaction Monitoring. Analytical Chemistry, 82, 548-558. http://dx.doi.org/10.1021/ac901790q

[26] Loyola-Vargas, V.M. and De Jimenez, E.S. (1984) Differential Role of Glutamate Dehydrogenase in Nitrogen Metabolism of Maize Tissues. Plant Physiology, 76, 536-540. http://dx.doi.org/10.1104/pp.76.2.536

[27] Osuji, G.O., Mangaroo, A.S., Reyes, J. and Wright, V. (2003/4) Biomass Enhancement in Maize and Soybean in Response to Glutamate Dehydrogenase Isomerization. Biologia Plantarum, 47, 45-52. http://dx.doi.org/10.1023/A:1027324713682

[28] Osuji, G.O., Konan, J. and M'Mbijjewe, G. (2004) RNA Synthetic Activity of Glutamate Dehydrogenase. Biotechnology and Applied Biochemistry, 119, 209-228. http://dx.doi.org/10.1007/s12010-004-0003-z

[29] Grierson, D., Slater, A., Speirs, J. and Tucker, G.A. (1985) The Appearance of Polygalacturonase RNA in Tomato: One of a Series of Changes in Gene Expression during Development and Ripening. Planta, 163, 263-271. 
http://dx.doi.org/10.1007/BF00393517

[30] Osuji, G.O., Brown, T.K. and South, S.M. (2009) Nucleotide-Dependent Reprogramming of mRNAs Encoding Acetylcoenzyme A Carboxylase and Lipoxygenase in Relation to Fat Contents of Peanut. Journal of Botany, 2009, Article ID: 278324. http://hindawi.com/journals/jb/2009/278324.html

[31] Law, R.D. and Plaxton, W.C. (1995) Purification and Characterization of a Novel Phosphoenolpyruvate Carboxylase from Banana Fruit. Biochemical Journal, 307, 807-816. http://dx.doi.org/10.1042/bj3070807

[32] Singal, H.R. and Singh, R. (1986) Purification and Properties of Phosphoenolpyruvate Carboxylase from Immature Pods of Chickpea (Cecer arietium L). Plant Physiology, 80, 369-373. http://dx.doi.org/10.1104/pp.80.2.369

[33] Beeching, J.R. and Northcote, D.H. (1987) Nucleic Acid (cDNA) and Amino Acid Sequences of Isocitrate Lyase from Castor Bean. Plant Molecular Biology, 8, 471-475. http://dx.doi.org/10.1007/BF00017992

[34] Comai, L., Diewtrich, R.A., Maslyar, D.J., Baden, C.S. and Harada, J.J. (1989) Coordinate Expression of Transcriptionally Regulated Isocitrate Lyase and Malate Synthase Genes in Brassica napus L. The Plant Cell, 1, 293-300.

[35] Mano, S., Hayashi, M., Kondo, M. and Nishimura, M. (1996) cDNA Cloning and Expression of a Gene for Isocitrate Lyase in Pumpkin Cotyledons. Plant \& Cell Physiology, 37, 941-948. http://dx.doi.org/10.1093/oxfordjournals.pcp.a029043

[36] Rodriguez, D., Ginger, R.S., Baker, A. and Nortcote, D.H. (1990) Nucleotide Sequence Analysis of a cDNA Clone Encoding Malate Synthase of Castor Bean (Ricinus communis) Reveals Homology to DAL7, a Gene Involved in Allantoin Degradation in Saccharomyces Cerevisiae. Plant Molecular Biology, 15, 501-504. http://dx.doi.org/10.1007/BF00019167

[37] Graham, I.A., Leaver, C.J. and Smith, S.M. (1992) Induction of Malate Synthase Gene Expression in Senescent and Detached Organs of Cucumber. The Plant Cell, 4, 349-357. http://dx.doi.org/10.1105/tpc.4.3.349

[38] Rothermel, B.A. and Nelson, T. (1989) Primary Structure of Maize NADP-Dependent Malic Enzyme. The Journal of Biological Chemistry, 246, 19587-19592.

[39] Schearer, H.L., Turpin, D.H. and Dennis, D.T. (2004) Characterization of NADP-Dependent Malic Enzyme from Developing Castor Oil Seed Endosperm. Archives of Biochemistry and Biophysics, 429, 134-144. http://dx.doi.org/10.1016/j.abb.2004.07.001

[40] Blakeley, S.D., Dekroon, C., Cole, K.P., Krml, M. and Dennis, D.T. (1994) Isolation of a Full-Length cDNA Encoding Cytosolic Enolase from Ricinus communis. Plant Physiology, 105, 455-456. http://dx.doi.org/10.1104/pp.105.1.455

[41] Vander Straeten, D., Rodrigues-Pousada, R.A., Goodman, H.M. and Van Montagu, M. (1991) Plant Enolase: Gene Structure, Expression, and Evolution. The Plant Cell, 3, 719-735. http://dx.doi.org/10.1105/tpc.3.7.719

[42] Cerff, R. and Chambers, S.E. (1979) Subunit Structure of Higher Plant Glyceraldehyde-3-Phosphate Dehydrogenase (EC 1.2.1.12 and EC 1.2.1.13). The Journal of Biological Chemistry, 254, 6094-6098.

[43] Russell, D.A. and Sachs, M.M. (1989) Differential Expression and Sequence Analysis of the Maize Glyceraldehyde-3-Phosphate Dehydrogenase Gene Family. The Plant Cell, 1, 793-803. http://dx.doi.org/10.1105/tpc.1.8.793

[44] Grana, X., Broceno, C., Garriga, J., de la Ossa, P.P. and Climent, F. (1993) Phosphoglycerate Mutase Activity and mRNA Levels during Germination of Maize Embryos. Plant Science, 89, 147-151. http://dx.doi.org/10.1016/0168-9452(93)90122-G

[45] Huang, Y., Blakeley, S.D., McAleese, S.M., Fothergill-Gilmore, L.A. and Dennis, D.T. (1993) Higher Plant Cofactor-Independent Phosphoglyceromutase: Purification, Molecular Characterization and Expression. Plant Molecular Biology, 23, 1039-1053. http://dx.doi.org/10.1007/BF00021818

[46] Osuji, G.O. and Brown, T. (2007) Role of the RNAs Synthesized by Glutamate Dehydrogenase in the Coordinate Regulation of Metabolic Processes. The Icfai Journal of Biotechnology, 1, 37-48.

[47] Young, C.T. (1980) Amino Acid Composition of Three Commercial Peanut Varieties. Journal of Food Science, 45, 1086-1087. http://dx.doi.org/10.1111/j.1365-2621.1980.tb07527.x

[48] His, D.C.H., Young, C.T. and Ortiz, M. (1981) Effect of Growing Season, Locations and Planting Dates on Total Amino Acid Composition of Two Valencia Peanut Varieties Grown in New Mexico. Peanut Science, 8, 131-133. http://dx.doi.org/10.3146/i0095-3679-8-2-14

[49] Young, C.T. and Waller, G.R. (1973) Variations in Total Amino Acid Content of Peanut Meal. Journal of the American Oil Chemists' Society, 50, 521-523. http://dx.doi.org/10.1007/BF02640524

[50] Perl, A., Shaul, O. and Galili, G. (1992) Regulation of Lysine Synthesis in Transgenic Potato Plants Expressing a Bacterial Dihydrodipicolinate Synthase in Their Chloroplasts. Plant Molecular Biology, 19, 815-824. http://dx.doi.org/10.1007/BF00027077

[51] Averous, J., Lambert-Langlais, C., Chaveroux, C., Perry, L., Carraro, V., Maurin, A.-C., Jousse, C. and Fafournoux, P. 
(2012) Cellular Adaptation to Amino Acid Availability: Mechanisms Involved in the Regulation of Gene Expression. In: D’Mello, J.P.F., Eds., Amino Acids in Human Nutrition and Health, CABI Publishers, Oxfordshire and Boston, 229-242.

[52] Walker, M.E. and Ethredge, J. (1974) Effects of N Rate and Application on Spanish Peanut (Arachis hypogaea L.) Yield and Seed Grade, N and Oil. Peanut Science, 1, 45-47. http://dx.doi.org/10.3146/i0095-3679-1-2-2 